\title{
ECONOMIC BURDEN OF VIRAL ACUTE RESPIRATORY INFECTIONS IN UPPER-MIDDLE-INCOME COUNTRIES: PROTOCOL FOR A SYSTEMATIC REVIEW
}

\author{
César Ramos Rocha-Filho'; Aline Pereira da Rochall; Felipe Sebastião de Assis \\ Reis"II; Ana Carolina Pereira Nunes Pintolv; Gabriel Sodré Ramalhov; Giulia \\ Fernandes Moça Trevisanivl; Laura Jantsch FerlaVII; Maria Eduarda Santos \\ PugaVIII; Luci CorrealX Virgínia Fernandes Moça Trevisanix; Márcia Mello Costa \\ De Liberal ${ }^{\mathrm{x}}$; Álvaro Nagib AtallahXII
}

\begin{abstract}
'MSc, Health Care and Health Assessment. PhD Student, Evidence-Based Health Program, Universidade Federal de São Paulo (UNIFESP). Volunteer Researcher, Cochrane Brazil, São Paulo (SP), Brazil. https://orcid.org/0000-0002-7190-0263.
\end{abstract}

" MSc, Pharmacist. PhD Student, Evidence-Based Health Program, Universidade Federal de São Paulo (UNIFESP). Volunteer Researcher, Cochrane Brazil, São Paulo (SP), Brazil. http://orcid.org/0000-0002-0863-6500.

III MD, MPS, Technologies and Healthcare. Manager, Medical Practices, Beneficência Portuguesa de São Paulo, São Paulo (SP), Brazil. https://orcid.org/0000-0002-5728-4863.

Iv MSc, Physiotherapist. PhD Student, Evidence-Based Health Program, Universidade Federal de São Paulo (UNIFESP). Professor, Biological and Health Sciences Department, Universidade Federal do Amapá (AP), Brazil. Volunteer Researcher, Cochrane Brazil, São Paulo (SP), Brazil. http://orcid.org/0000-0002-1505-877X.

$\checkmark$ Undergraduate Medical Student, Escola Paulista de Medicina (EPM), Universidade Federal de São Paulo (UNIFESP), São Paulo (SP), Brazil. https://orcid.org/0000-0001-7201-2308.

VI Undergraduate Medical Student, Universidade Santo Amaro, São Paulo (SP), Brazil. https://orcid.org/0000-0003-3581-3047.

VII Undergraduate Medical Student, Escola Paulista de Medicina (EPM), Universidade Federal de São Paulo (UNIFESP), São Paulo (SP), Brazil. https://orcid.org/0000-0002-8162-2068.

VIII MSc, PhD. Librarian, Evidence-Based Health Program, Universidade Federal de São Paulo (UNIFESP), São Paulo (SP), Brazil. Volunteer Researcher, Cochrane Brazil, São Paulo (SP), Brazil. https://orcid.org/0000-0001-8470-861X.

IX MD, MSc, PhD Infectologist. Professor, Discipline of Infectiology, Escola Paulista de Medicina (EPM), Universidade Federal de São Paulo (UNIFESP), São Paulo (SP), Brazil. https://orcid.org/0000-0002-6404-3072.

$\times$ MD, MSc, PhD Rheumatologist. Professor, Discipline of Emergency and Evidence-Based Medicine, Escola Paulista de Medicina (EPM), Universidade Federal de São Paulo (UNIFESP). Researcher, Cochrane Brazil, São Paulo (SP), Brazil. http://orcid.org/0000-0002-7180-6285.

$\mathrm{XI}$ MSc, PhD, Economist. Professor, Discipline of Economy and Health Management, Escola Paulista de Medicina (EPM), Universidade Federal de São Paulo (UNIFESP). Researcher, Cochrane Brazil, São Paulo (SP), Brazil. https://orcid.org/0000-0002-2589-1802.

XII MD, MSc, PhD. Nephrologist and Full Professor, Discipline of Emergency and EvidenceBased Medicine, Escola Paulista de Medicina (EPM), Universidade Federal de São Paulo (UNIFESP). Director, Cochrane Brazil, São Paulo (SP), Brazil. http://orcid.org/0000-0003-0890594X. 


\section{Abstract}

Objective: To synthesize the available data on the economic burden of Coronavirus Diseases 2019 (COVID-19), Severe Acute Respiratory Syndrome (SARS), Middle East Respiratory Syndrome (MERS), Influenza-Like Illness (ILI), Respiratory Syncytial Virus (RSV)-related Acute Respiratory Infection (ARI), and Parainfluenza Virus type III (PIV3)-related ARI in Upper-MiddleIncome Countries (UMIC), highlighting its major causes and comparing direct costs among nations. Study design: Systematic review, following the recommendations proposed in the Cochrane Handbook, but with some adaptations from previous economic studies. Review question: Is there any economic cost of viral ARI in UMIC? Types of studies to be included: Partial economic evaluation, such as Cost-of-Illness (COI) studies and burden of illness/diseases, database analysis, observational reports (cross-sectional studies, and prospective and retrospective cohort), and economic modelling studies that discuss one of the viral ARI in UMIC. No year of publication filter or language limit will be applied. Search databases: MEDLINE, EMBASE, LILACS, CINAHL, EconLit, CRD Library, MedRxiv, and Research Square. Moreover, hand searches of the bibliographies of included studies and relevant reviews identified during the screening process will be undertaken to identify any additional relevant study for inclusion in our review. Synthesis of results: Qualitative analysis. We will focus on the overall economic burden of the diseases on health systems and population; total direct cost; the contribution of different cost components to the economic burden (e.g. pharmacological therapy, hospitalization); comparative assessments of costs analysis across geographical location and time horizon; and current research gaps. Moreover, we intend to identify, when presented, prevalence and incidence rates of each disease. PROSPERO registration number: CRD42020225757.

Keywords: Acute respiratory infection; Economic burden; COVID-19; Developing Countries; Systematic Review. 
medRxiv preprint doi: https://doi.org/10.1101/2020.12.14.20248198; this version posted December 16, 2020. The copyright holder for this

\section{Background}

Acute Respiratory Infections (ARI) are a worldwide threat responsible for more than four million deaths annually [1]. The pathogenicity is typically caused by a virus, bacteria, fungi, or a mix of these microorganisms [2]. Although knowledge of modes of transmission is ever-evolving, scientific consensus reports airborne transmission by droplets and contact as the main acquisition routes of most respiratory infection diseases, especially viral ARI $[1,2]$.

According to the World Lung Foundation, mortality rates of viral ARI are particularly high in the youngest and oldest people in low- and middle-income nations [1]. In this context, the geographical setting presents itself as a host factor due to the inadequate availability and effectiveness of medical care and infection prevention, and control measures of these countries to contain spread, such as vaccines, access to health-care facilities, and capacity of isolation at the hospitals and outpatient settings (or home settings) [2].

Due to the high and increasing incidence and prevalence rates, viral ARI represents an enormous economic burden in healthcare systems, independently of income classification [1-3]. To contextualize, an economic burden of diseases is related to the financial loss of individuals, families, societies, and governments due to economic resources spent related to respond to the diseases $[3,4]$.

Outbreaks such as Severe Acute Respiratory Syndrome (SARS) in 2003 [5], and more recently the Coronavirus Disease 2019 (COVID-19) pandemic in December 2019 [6], have shown the burden that viral ARI can inflict in healthcare systems and national economies. In this scenario, valid estimates of the Cost-of-Illness (COI) in different perspectives are of particular importance and necessity to justify preventive and intervention-based programs. In the same way, estimates of the overall health system economic impact of viral ARI help to understand what specific factors are driving these costs, and may inform decision-makers to support formulation and refinement of policies $[3,4,7,8]$.

\section{Objectives}

Our aim is to synthesize the available data on the economic burden of six viral ARI in Upper-Middle-Income Countries (UMIC), highlighting its major causes and comparing direct costs among nations. 


\section{Methods}

\section{Study design and registration}

The synthesize process will be based on the methodological process of a systematic review. To the best of our knowledge, there is no formal guideline to perform a systematic review of economic evaluations $[4,7,9]$. Thus, we will follow the well-established recommendations proposed in the Cochrane Handbook [10], but with some adaptations from studies performed by previously authors $[4,7,9,11,12]$. The main modifications included quality assessment and data analysis process.

This protocol is registered in the PROSPERO "International Prospective Register of Systematic Reviews" (CRD42020225757) and structured following the Preferred Reporting Items for Systematic Review and Meta-Analysis (PRISMA) Protocols guidance [13].

\section{Definition of the research question}

The research question was structured in an iterative way to reflect the critical points related to the economic burden of six viral ARI in UMIC. We accepted a decision-maker perspective and pursued to identify comparative indicators.

Thus, our systematic review will aim to answer the following research question: Is there any economic cost of viral ARI in UMIC? Moreover, we intend to identify the major costs drivers related to viral ARI in different countries with sociodemographic similarities.

\section{Criteria for considering studies for this review}

A study will be eligible for inclusion if it presents a burden estimation, in monetary units, of one of the choose viral ARI in an UMIC. Thus, our systematic review will present three main "sets" of interest: economic evidence, viral ARI and UMIC. Table 1 details the definitions that will be adopted. 
medRxiv preprint doi: https://doi.org/10.1101/2020.12.14.20248198; this version posted December 16,2020 . The copyright holder for this preprint (which was not certified by peer review) is the author/funder, who has granted medRxiv a license to display the preprint in perpetuity.

Table 1. Definitions adopted in this systematic review to select and categorize studies.

\section{Economic evidence}

Study design

Cost-of-Illness study

Economic analysis evaluating the region or countrylevel economic consequences that the presence of disease and its outcomes exert on individuals and society [4].

Economic modelling

Mathematical model (+/- simulation) extrapolating primary data to produce original estimates beyond their original scope, e.g. time and location [4].

Database analysis

Analysis of patient records from an already existing database, e.g. health insurance claims, hospital reimbursements [4].

Prospective cost study Cost study informed by data gathered from a prospective cohort of patients [4].

Retrospective cost study Cost study informed by data collected from a retrospective cohort of patients, e.g. medical records, case notes [4].

\section{Cost component}

Direct medical costs

Medically related inputs used directly to provide the treatment of disease, including costs associated with the diagnosis, pharmacological and nonpharmacological treatment, hospitalization, outpatient fees, continuing care, rehabilitation etc [11].

Direct nonmedical costs Costs to patients and their families that are directly associated with a disease but are not medical in nature, including transportation costs, out-of-pocket expenses, costs for household expenditures, and informal care [11].

Indirect costs

Economic burden related to the consequence or outcome of disease, such as lost productivity, sick leave, early retirement, unemployment, professional reorientation [11].

Intangible costs

Includes social, emotional, and human costs. In general, these are unmeasurable costs that cannot be converted to monetary units, such as pain, suffering, or poor emotional health [11].

\section{Economic perspective}

Individual

Direct costs incurred only by patients or family members (e.g. out-of-pocket payments) [4].

Provider

Costs incurred by the health care provider (e.g. average unit cost of an inpatient day) [4].

Third-party payer

Costs incurred at the level of a third-party payer (e.g. insurance fund, Ministry of Health) [4]. 
medRxiv preprint doi: https://doi.org/10.1101/2020.12.14.20248198; this version posted December 16,2020 . The copyright holder for this preprint (which was not certified by peer review) is the author/funder, who has granted medRxiv a license to display the preprint in

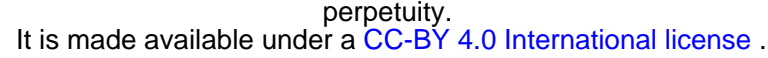

Societal

Other

Unclear

Study scope

Institutional

Municipal

Regional

National

International

Other
Study reporting some form of indirect cost, incurred at any level (e.g. value of lost productivity due to illness) [4].

Other perspectives (e.g. pharmaceutical sector) or multiple perspectives (e.g. patient and provider) [4].

Could not be determined based on the information provided.

Study conducted in one or more health care institutions, with no specified geographical setting below national level and no evidence of a sampling procedure to ensure representativeness [4].

Study conducted in health care facilities in a specified city [4].

Study conducted in health care facilities in a specified sub-national administrative unit (e.g. region, province, state) [4].

Study conducted at the national level, either through representative sampling of health care facilities or through modelling [4].

Multi-country cost-analysis mixing different income classification, e.g. low-income and high-income countries [4].

Other than above or multiple categories.

\section{Viral acute respiratory infectious}

Coronavirus Diseases 2019 (COVID-19)

Severe Acute Respiratory Syndrome (SARS)

Middle East Respiratory Syndrome (MERS)
Disease caused by the Severe Acute Respiratory Syndrome Coronavirus 2 (SARS-CoV-2). Common symptoms are fever, dry cough, and fatigue. Other symptoms that are less common involve anosmia, hyposmia, dysgeusia, diarrhea, and different types of skin rash [6].

Disease caused by the Severe Acute Respiratory Syndrome coronavirus (SARS-CoV). Most reported symptoms are influenza-like and include fever, malaise, myalgia, headache, diarrhea, and shivering (rigors). Severe cases often evolve rapidly, progressing to respiratory distress and requiring intensive care [5].

Disease caused by the virus Middle East Respiratory Syndrome Coronavirus (MERS-CoV). Typical symptoms include fever, cough, and shortness of breath. Pneumonia and gastrointestinal symptoms are also commonly reported [14]. 
medRxiv preprint doi: https://doi.org/10.1101/2020.12.14.20248198; this version posted December 16,2020 . The copyright holder for this preprint (which was not certified by peer review) is the author/funder, who has granted medRxiv a license to display the preprint in perpetuity.

Influenza-Like IIIness (ILI)

Respiratory Syncytial Virus (RSV)-related $\mathrm{ARI}$

Parainfluenza Virus type III (PIV3)-related ARI
WHO case definitions for ILI have changed many times [15]. As no year of publication will be settled to screen for studies in our review, we will adopt the most reported, which are:

- WHO 1999: "a sudden onset of fever, a temperature $>38^{\circ} \mathrm{C}$ and a cough or sore throat in the absence of another diagnosis".

WHO 2018: "an acute respiratory illness with measured temperature of $\geq 38^{\circ} \mathrm{C}$ and cough, with onset within 10 days" [15].

RSV is an RNA virus, classified as a pneumovirus. Is considered the most common cause of lower respiratory tract illness in young infants. The illness commonly manifest are bronchiolitis and pneumonia. These illnesses typically begin with upper respiratory symptoms and fever, then progress over several days to dyspnea, cough, wheezing, and/or crackles on chest auscultation [16].

Most frequently among young infants and immunocompromised children and adults. This type of infection may present pneumonia and/or bronchiolitis clinical syndromes [17].

\section{Upper-middle-income countries}

2019 GNI per capita between $\$ 4,046$ and $\$ 12,535[18]$
Albania; American Samoa; Argentina; Armenia; Azerbaijan; Belarus; Belize; Bosnia and Herzegovina; Botswana; Brazil; Bulgaria; China; Colombia; Costa Rica; Cuba; Dominica; Dominican Republic; Ecuador; Equatorial Guinea; Fiji; Gabon; Georgia; Grenada; Guatemala; Guyana; Indonesia; Iran, Islamic Rep.; Iraq; Jamaica; Jordan; Kazakhstan; Kosovo; Lebanon; Libya; Malaysia; Maldives; Marshall Islands; Mexico; Montenegro; Namibia; North Macedonia; Paraguay; Peru; Russian Federation; Samoa; Serbia; South Africa; St. Lucia; St. Vincent and the Grenadines; Suriname; Thailand; Tonga; Turkey; Turkmenistan; Tuvalu; Venezuela, RB [18].

ARI: Acute Respiratory Infections; GNI: Gross National Income; WHO: World Health Organization.

For the economic evidence set, we will evaluate the economic perspective, study scope, and study design of manuscripts for inclusion. From an economic perspective, we will accept individual, provider, societal, or thirdparty payers. For study scope, reports that estimate costs at institutional, municipal, regional, or national level will be included for analysis [7]. Multicountry studies (international scope) will be included only if they provide an 
medRxiv preprint doi: https://doi.org/10.1101/2020.12.14.20248198; this version posted December 16, 2020. The copyright holder for this preprint (which was not certified by peer review) is the author/funder, who has granted medRxiv a license to display the preprint in It is made available under a CC-BY 4.0 International license .

explicit, distinguished, and detailed economic estimate for one of the UMIC investigated (Table 1).

Considering study design, we will include partial economic evaluation, such as $\mathrm{COI}$ studies and burden of illness/diseases, database analysis, observational reports (cross-sectional studies, and prospective and retrospective cohort), and economic modelling studies [7]. Due to the diversity of geographical settings that will be investigated, and aiming for a comparative assessment of costs analysis, we will only include studies that present cost components (Table 1) in disjointed analysis. There will be no restrictions on the time horizon for the studies, language, year of publication, or publication status.

We will exclude letters, reviews, commentaries, editorials, case reports, case series, and papers without sufficient information to clearly identify methods, sources, or unit costs. Complete economic evaluations studies, such as cost-effectiveness, cost-utility, cost-benefit, and cost-minimization analysis will also be excluded. Moreover, clinical trials of interventions with economic evidence, and studies that presented proposals for new prevention measures, assuming the cost that could generate, will not be included.

Our exclusion criteria will also be applied to studies that measure and report alone intangible costs, indirect costs, or societal economic perspective (Table 1), due to the difficulties of accurately quantifying certain costs and comparing social and cultural characteristics between different nations. In like manner, we will exclude epidemiological studies using disability-adjusted life years as result [7]. In view of our goal to identify the economic impact of the history of disease, cost analysis that estimate financial burden on government assistance programs during a health crisis, such as COVID-19 pandemic, will also be excluded.

Conference and journals abstract that meet the eligible criteria will be directly included if a complete extraction of data and quality analysis can be performed. In case of insufficient data, we will contact the authors of involved study to solicit relevant information. A period of three months for response will be established. If there is no return or any impossibility within the contact, the study will be included into the review and filed in "Studies Awaiting Classification". The same label will be applied to non-English language reports 
medRxiv preprint doi: https://doi.org/10.1101/2020.12.14.20248198; this version posted December 16, 2020. The copyright holder for this

from which it is not possible to perform a valid translation and, therefore, the systematic evaluation [19].

For the viral ARI set, we will adopt the definitions presented by the WHO guidelines for infection prevention and control of epidemic- and pandemic-prone ARI in health care [2]. Thus, we will search for diseases that cause acute respiratory tract infection in humans, including pneumonia and/or acute respiratory distress syndrome (e.g. bronchiolitis); cause severe complications in susceptible individuals with apparently normal immune defense systems; are caused by a viral microorganism; and may constitute a public health emergency of international concern. Therefore, the following viral ARI will be included: COVID-19, SARS, Middle East Respiratory Syndrome (MERS), Influenza-Like Illness (ILI), Respiratory Syncytial Virus (RSV)-related ARI, and Parainfluenza Virus type III (PIV3)-related ARI. The definitions adopted to characterize the diseases are presented in Table 1.

Studies conducted on other types of viral ARI than established in our review (Table 1), such as laryngitis, pharyngitis, rhinitis, viral ARI in nonhumans etc., will be excluded. Furthermore, economic evaluations that included one of our viral ARI investigated as secondary infection will be excluded if they do not report the costs in a distinguished manner.

Finally, the UMIC set will follow the classification established by the World Bank, according to 2019 Gross National Income (GNI) per capita. Thus, we will include in our review countries that presented a GNI per capita between $\$ 4,046$ and $\$ 12,535$ [18]. Table 1 details the list of the included countries.

\section{Search methods for identification of studies}

Our search for economic shreds of evidence will be performed in five main databases: the Medical Literature Analysis and Retrieval System Online (MEDLINE); Excerpta Medica database (EMBASE); Latin American and Caribbean Health Sciences Literature (LILACS); Cumulative Index of Nursing and Allied Health Literature (CINAHL), and EconLit. Considering the cost analysis topic of investigation, a more broadly specified search will be performed in The Centre for Review and Dissemination (CRD) Library, incorporating the Database of Abstracts of Reviews of Effects (DARE), the 
medRxiv preprint doi: https://doi.org/10.1101/2020.12.14.20248198; this version posted December 16, 2020. The copyright holder for this preprint (which was not certified by peer review) is the author/funder, who has granted medRxiv a license to display the preprint in

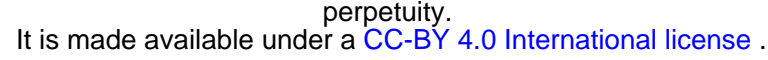

National Health Service (NHS) Economic Evaluation (NHS EED), and NHS Health Technology Assessment (NHS HTA) databases [20].

Moreover, we will also search for evidence in the preprint server for Health Sciences, MedRxiv, and the preprint platform Research Square. Finally, hand searches of the bibliographies of included studies and relevant reviews identified during the screening process will be undertaken to identify any additional relevant study for inclusion in our review [10].

The search strategy will be developed with the guidance of an expert research librarian (MESP). The sensible structure will include and combine the three main "sets" of interest of this review: economic evidence, viral ARI, and UMIC. For the economic evidence search strategy, we will adapt the search filters provided by Shemilt and collaborators [20] in the Cochrane Handbook, and combine strategies developed by other authors in previously systematic reviews of economic burden $[4,11]$. For the viral ARI set, the search strategy will be based on controlled vocabulary for each disease. Lastly, UMIC search terms will follow the list of the World Bank [18] and controlled vocabulary related to developing countries $[4,11]$. No year of publication filter will be applied.

The search strategy that will be applied to MEDLINE (via PubMed) is shown in Table 2. Adaptations of this search strategy will be taken across the different databases. A detailed strategy for each of the databases will be published in the final review.

Table 2. Search strategy for MEDLINE (via PubMed).

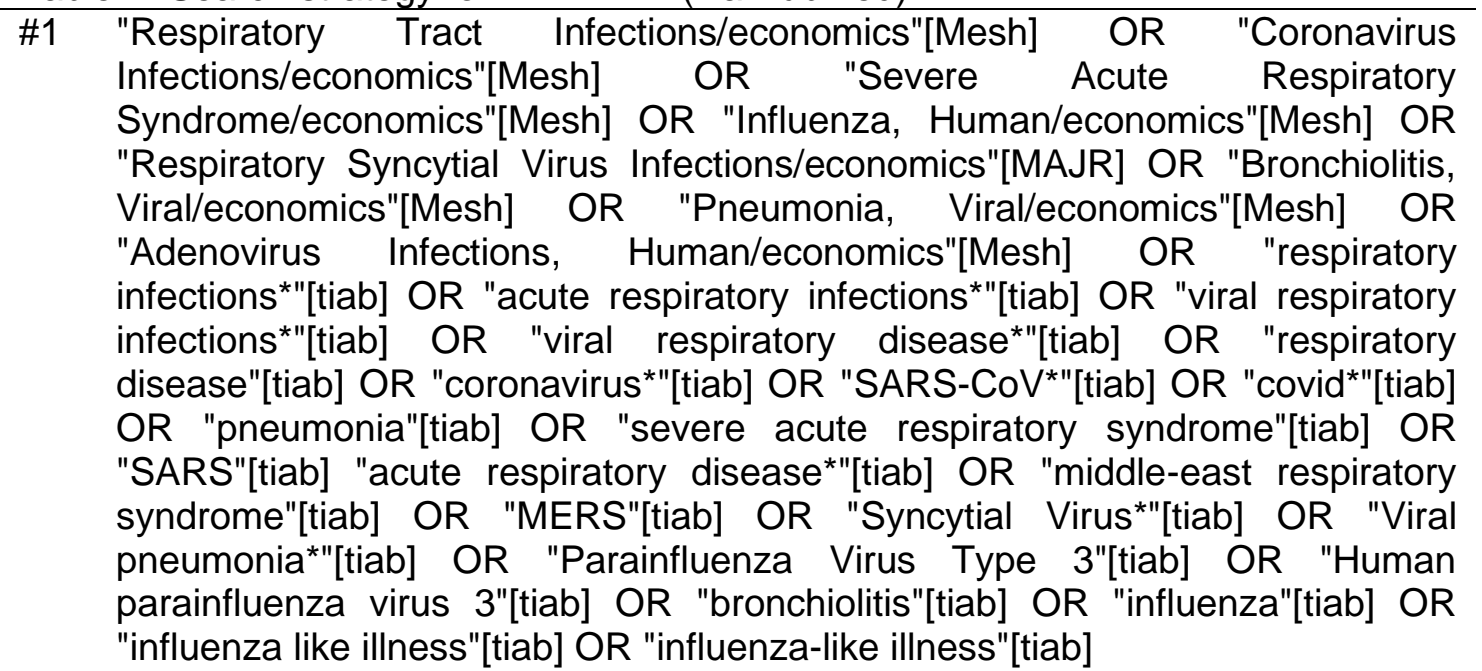


medRxiv preprint doi: https://doi.org/10.1101/2020.12.14.20248198; this version posted December 16, 2020. The copyright holder for this preprint (which was not certified by peer review) is the author/funder, who has granted medRxiv a license to display the preprint in perpetuity.

It is made available under a CC-BY 4.0 International license .

\#2 "Developing Countries/economics"[Mesh] OR "middle-income"[tiab] OR "uppermiddle-income"[tiab] OR "least developed countries"[tiab] OR "under developed nation*"[tiab] OR "third-world*"[tiab] OR "thirdworld""[tiab] OR "3rdworld"[tiab] OR "Albania"[tiab] OR "American Samoa"[tiab] OR "Argentina"[tiab] OR "Armenia"[tiab] OR "Azerbaijan"[tiab] OR "Belarus"[tiab] OR "Belize"[tiab] OR "Bosnia and Herzegovina"[tiab] OR "Botswana"[tiab] OR "Brazil"[tiab] OR "Bulgaria"[tiab] OR "China"[tiab] OR "Colombia"[tiab] OR "Costa Rica"[tiab] OR "Cuba"[tiab] OR "Dominica"[tiab] OR "Dominican Republic"[tiab] OR "Ecuador"[tiab] OR "Equatorial Guinea"[tiab] OR "Fiji"[tiab] OR "Gabon"[tiab] OR "Georgia"[tiab] OR "Grenada"[tiab] OR "Guatemala"[tiab] OR "Guyana"[tiab] OR "Indonesia"[tiab] OR "Iran"[tiab] OR "Islamic*"[tiab] OR "Iraq"[tiab] OR "Jamaica"[tiab] OR "Jordan"[tiab] OR "Kazakhstan"[tiab] OR "Kosovo"[tiab] OR "Lebanon"[tiab] OR "Libya"[tiab] OR "Malaysia"[tiab] OR "Maldives"[tiab] OR "Marshall Islands"[tiab] OR "Mexico"[tiab] OR "Montenegro"[tiab] OR "Namibia"[tiab] OR "North Macedonia"[tiab] OR "Paraguay"[tiab] OR "Peru"[tiab] OR "Russian*"[tiab] OR "Samoa"[tiab] OR "Serbia"[tiab] OR "South Africa"[tiab] OR "Saint Lucia"[tiab] OR "Saint Vincent*"[tiab] OR "Suriname"[tiab] OR "Thailand"[tiab] OR "Tonga"[tiab] OR "Turkey"[tiab] OR "Turkmenistan"[tiab] OR "Tuvalu"[tiab] OR "Venezuela*"[tiab]

\#3 "Economic*"[tiab] OR "Income*"[tiab] OR "Expenditure*"[tiab] OR "cost-ofillness"[tiab] OR "cost of illness"[tiab] OR "cost of sickness"[tiab] OR "financial burden"[tiab] OR "financial impact"[tiab] OR "economic burden"[tiab] OR "burden of illness"[tiab] OR "out-of-pocket*"[tiab] OR "health expenditure*"[tiab] OR "budget""[tiab] OR "fee*"[tiab] OR "direct cost""[tiab] OR "cost allocation"[tiab] OR "payment*"[tiab] OR "cost analysis"[tiab] OR "macroeconomic*"[tiab] OR "microeconomic*"[tiab] OR "pricing"[tiab] OR "cost measures"[tiab] OR "Cost measure*"[tiab] OR "Illness Burden*"[tiab] OR "sickness cost*"[tiab] OR "disease cost""[tiab] OR "Illness cost*"[tiab] OR "direct service cost*"[tiab] OR "service cost*"[tiab] OR "hospital charge*"[tiab] OR "hospital cost*"[tiab] OR "hospitalization cost""[tiab] OR "medical cost*"[tiab] OR "medical care cost" [tiab] OR "health care cost""[tiab] OR "medical burden"[tiab] OR "expense"[tiab] OR "spending"[tiab]

\#1 AND \#2 AND \#3

\section{Selection of studies}

The reports identified through our search strategy will be uploaded to the web application Rayyan (http://rayyan.qcri.org) [21]. After removing duplicates, two review authors (CRRF and one of ACPNP, APR, FSAR, GFMT or GSR) will independently screen titles and abstracts of all recovered studies against preestablished eligibility criteria. The selected studies will then be fully read, by the same review authors, for further scrutiny. We will exclude full-text articles that do not meet the eligibility criteria and then present reasons for exclusions in the final review. At all stages, disagreements between reviewers will be discussed and resolved consensually. If necessary, the opinion of a third reviewer (MMCL or VFMT) will be consulted. 
medRxiv preprint doi: https://doi.org/10.1101/2020.12.14.20248198; this version posted December 16, 2020. The copyright holder for this

If a same study, using the same sample and methods, is found in different published reports (e.g. abstract in congress, study protocol, and fulltext article), all of them will be included, but analyzed as a unique study. If different studies in a same population, with the same viral ARI investigated, are found completing overlapping time horizons, the report with the smaller period of analysis will be excluded. If a similar situation occurs without the temporal superposition, both reports will be included and analyzed as different studies.

\section{Data extraction and management}

For data extraction, we will follow a process of two stages. Firstly, two review authors ( $A P R$ and one of ACPNP, FSAR, GFMT or GSR) will extract and compile the data of each included study into a prestructured and piloted data collection form, designed specifically for this synthesis. Then, the completed forms will be reviewed by a third review author (CRRF) for accuracy and completeness. Discrepancies will be resolved by discussion and consensus among the authors.

In the event where there is missing data that we deem important, the corresponding author of the study will be contacted. The process will follow as previously presented for conferences and journals abstract inclusion. If the study fulfills all eligibility criteria but we receive no return within the contact, the label "Study Awaiting Classification" will be applied [19].

An initial version of the data collection form will be structured combining general information about the included studies, and elements of the three main "sets" of interest in our review [22]. More specifically, in this version we will extract information on: i) study identification (first author and year); ii) type of viral ARI investigated; iii) geographical setting (UMIC); iv) study design; v) study size (e.g. population-based studies or sampled-based studies); vi) population characteristics (e.g. age and gender); vii) epidemiological approach (prevalent or incident); viii) study scope (data source); ix) economic perspective; $x$ ) study duration/time horizon; xi) cost components; xii) total cost; xiii) cost conversion (see "standardization of cost data"); and xiv) conflicts of interest. Table 1 details the elements of each category and presents definitions. 
medRxiv preprint doi: https://doi.org/10.1101/2020.12.14.20248198; this version posted December 16, 2020. The copyright holder for this

We will pilot this initial version on a randomly selected sample of included studies (maximum five, if available), and then determine the final version. Modifications will be reported in the systematic review publication.

\section{Standardization of cost data}

To reach a better comparability between the different currencies, all reported costs in the included studies will be converted to Purchasing Power Parity (PPP)-adjusted US\$ 2021 (Int\$2021) [20]. For this, we will use the free online cost converter tool from Campbell and Cochrane Economics Methods Group Evidence for Policy and Practice Information and Coordination Centre (CCEMG-EPPI Centre) (https://eppi.ioe.ac.uk/costconversion/) [23].

When the base year of the currency is not reported or cannot be inferred from the manuscript (e.g. last year of data collection), it will be assumed as reference year the year before the publication of the manuscript. For studies presenting estimates for more than one year, the most recent estimate will be extracted. No adjustment will be made to economic outcomes expressed as ratios or percentages, e.g. percentage of Gross Domestic Product (GDP) [4].

\section{Quality assessment}

After extraction, the quality of included studies will be appraised independently by two review authors (CRRF and MMCL). Discrepancies will be solved by consensus and, if necessary, a third review author will be consulted (ANA or VFMT).

As previously reported, to the best of our knowledge, there is currently no formal guideline or consensus on recommended tools or checklists to assess the quality of studies that report the economic burden of diseases $[4,7,9]$. In our review, we will follow the checklist used by Oliveira, Itria, and Lima [9], that was based on the protocol proposed by the British Medical Journal (BMJ) [24], and on the Consolidated Health Economic Evaluation Reporting Standards (CHEERS), version 2013, developed by the International Society for Pharmacology and Outcomes Research (ISPOR) [25].

The checklist is structured in three blocks of questions, totalizing 29 items that aim to characterize a health cost analysis. The first block contains 11 items referred to the study design. The second block analyzes the data 
collection process of each study in 9 items. Lastly, the third block performs the analysis and interpretation of the results in 9 items. Each item is rated in three grades: "yes", "no", and "not applicable". At the end of the classification, a relative value of each of these grades is settled for each study. The goal is to check the percentages of "yes" for each question [9].

\section{Summary measures and synthesis of results}

Due to the expected heterogeneity of the investigated topic in terms of design, study object, setting, methodological perspective and other characteristics, a quantitative synthesis of the burden estimates is unlikely to be appropriate. Thus, the results of included studies will be interpreted qualitatively in a narrative synthesis.

The main aspect of aggregation will be the type of viral ARI: COVID-19, SARS, MERS, ILI, RSV-related ARI, or PIV3-related ARI. We will then focus on the overall economic burden of the diseases on health systems and population; total direct cost; the contribution of different cost components to the economic burden (e.g. pharmacological therapy, hospitalization); comparative assessments of costs analysis across geographical location and time horizon; and current research gaps. Moreover, we intend to identify, when presented, prevalence and incidence rates of each disease. We will follow the PRISMA statement and checklist to undertake and report the findings of our systematic review [13].

\section{Discussion and study limitations}

There are some goals that we believe that our systematic review may achieve. Firstly, we will present the economic burden viral ARI to health systems, patients, and even society. If possible, we would like to report how these cost impacts on GDP of countries, aiming to present data to support the development of programs to respond to viral ARI.

When comparing and identifying major costs drives related to a viral ARI in different countries with sociodemographic similarities, we expect to point out perspectives and actions that may or may not have worked successfully. The same expectation is applicable to analyze different time horizons in the same 
country. These lessons may inform decision-makers and researchers to support formulation and refinement of policy and research objectives in viral ARI.

We anticipate some limitations in our study related to bias in viral ARI reporting and estimating burden of the diseases. As COVID-19 is an emerging public health concern, with many topics still under discovery, we may encounter a lack of studies or incomplete analysis with dubious results. We intend to overcome these limitations with a sensible analysis of the quality and relevance of included studies, and a further update of this systematic review two years after the first publication.

Finally, we intend to share our findings in conferences, peer-review journals, and social media platforms.

\section{Support for the review}

This study has the support of the Coordenação de Aperfeiçoamento de Pessoal de Nível Superior - Brasil (CAPES).

\section{References}

1. Mayor S. Acute respiratory infections are world's third leading cause of death. BMJ. 2010 Nov 9;341(1):c6360. doi: 10.1136/bmj.c6360.

2. World Health Organization(WHO). Infection prevention and control of epidemic- and pandemic-prone acute respiratory infections in health care. WHO Guideline. 2014.

3. Tanimura $T$, Jaramillo $E$, Weil D, Raviglione $M$, Lönnroth K. Financial burden for tuberculosis patients in low- and middle-income countries: A systematic review. Eur Respir J. 2014.

4. Gheorghe A, Griffiths U, Murphy A, Legido-Quigley H, Lamptey P, Perel $P$. The economic burden of cardiovascular disease and hypertension in low- and middle-income countries: a systematic review. BMC Public Health. 2018;18(1):975. doi: 10.1186/s12889-018-5806-x.

5. World Health Organization. SARS (Severe Acute Respiratory Syndrome) [Internet]. [cited 2020 Nov 11]; Available from: https://www.who.int/ith/diseases/sars/en.

6. World Health Organization. Coronavirus disease (COVID-19) [Internet]. 12 Oct. 2020 [cited 2020 Nov 11]; Available from: 
https://www.who.int/emergencies/diseases/novel-coronavirus-

2019/question-and-answers-hub/q-a-detail/q-a-

coronaviruses\#: :text=symptoms.

7. Zhu TY, Tam LS, Li EK. Cost-of-illness studies in systemic lupus erythematosus: A systematic review. Arthritis Care Res. 2011 May;63(5):751-60. doi: 10.1002/acr.20410.

8. Withrow D, Alter DA. The economic burden of obesity worldwide: a systematic review of the direct costs of obesity. Obes Rev. 2011 Feb;12(2):131-41.

9. Oliveira LN da S, Itria A, Lima EC. Cost of illness and program of dengue: A systematic review. PLoS One. 2019;14(2):e0211401. doi: 10.1371/journal.pone.0211401.

10. Higgins JPT, Thomas J, Chandler J, Cumpston M, Li T, Page MJ, Welch VA (editors). Cochrane Handbook for Systematic Reviews of Interventions. $2^{\text {nd }}$ ed. Chichester (UK): John Wiley \& Sons; 2019.

11. Afroz A, Alramadan MJ, Hossain MN, Romero L, Alam K, Magliano DJ, et al. Cost-of-illness of type 2 diabetes mellitus in low and lower-middle income countries: a systematic review. BMC Health Serv Res. 2018 Dec 17;18(1):972. doi: 10.1186/s12913-018-3772-8.

12. Abizanda $P$, Sinclair $A$, Barcons $N$, Lizán L, Rodríguez-Mañas L. Costs of Malnutrition in Institutionalized and Community-Dwelling Older Adults: A Systematic Review. J Am Med Dir Assoc. 2016. Jan;17(1):17-23. doi: 10.1016/j.jamda.2015.07.005.

13. Moher D, Liberati A, Tetzlaff J, Altman DG, PRISMA Group. Preferred reporting items for systematic reviews and meta-analyses: the PRISMA statement. PLoS Med. 2009 Jul 21;6(7):e1000097.

14. World Health Organization. Middle East Respiratory Syndrome Coronavirus (MERS-CoV) [Internet]. 11 march. 2019 [cited 2020 Nov 11];Available from: https://www.who.int/news-room/factsheets/detail/middle-east-respiratory-syndrome-coronavirus-(mers-cov).

15. Fitzner J, Qasmieh S, Mounts AW, Alexander B, Besselaar T, Briand S, et al. Revision of clinical case definitions: influenza-like illness and severe acute respiratory infection. Bull World Health Organ. 2018 Feb 1;96(2):122-128. doi: 10.2471/BLT.17.194514. 
16. Tesini BL. Respiratory Syncytial Virus (RSV) and Human Metapneumovirus Infections [Internet]. MSD Man. 2019 [cited 2020 Dec 11];Available from: https://www.msdmanuals.com/professional/pediatrics/miscellaneous-viralinfections-in-infants-and-children/respiratory-syncytial-virus-rsv-andhuman-metapneumovirus-infections.

17. Tesini BL. Parainfluenza Virus Infections [Internet]. MSD Man. 2020 [cited 2020 Nov 12];Available from:

https://www.msdmanuals.com/professional/infectiousdiseases/respiratory-viruses/parainfluenza-virus-infections.

18. The World Bank. World Bank Country and Lending Groups [Internet]. [cited $2020 \quad$ Nov 11];Available from: https://datahelpdesk.worldbank.org/knowledgebase/articles/906519world-bank-country-and-lending-groups.

19. Lefebvre C, Glanville J, Briscoe S, Littlewood A, Marshall C, Metzendorf M-I, et al. Chapter 4: Searching for and selecting studies. In: Higgins JPT, Thomas J, Chandler J, Cumpston M, Li T, Page MJ, et al., editors. Cochrane Handbook for Systematic Reviews of Interventions. Chichester (UK): John Wiley \& Sons; 2019. p. 67-108.

20. Shemilt I, Aluko P, Graybill E, Craig D, Henderson C, Drummond M, et al. Chapter 20: Economic evidence. In: Higgins J, Thomas J, Chandler J, Cumpston M, Li T, Page M, et al., editors. Cochrane Handbook for Systematic Reviews of Interventions. Chichester (UK): John Wiley \& Sons; 2019. p. 507-524.

21. Ouzzani M, Hammady H, Fedorowicz Z, Elmagarmid A. Rayyan-a web and mobile app for systematic reviews. Syst Rev. 2016;5(1):210. doi: 10.1186/s13643-016-0384-4.

22. Shi L, Zhong L, Cai Y. Economic burden of smoking-attributable diseases in China: A systematic review. Tob Induc. Dis. 2020 May 12;18(May). doi: 10.18332/tid/120102.

23. Shemilt I, Thomas J, Morciano M. A web-based tool for adjusting costs to a specific target currency and price year. Evidence and Policy. 2010 Jan 1;6(1):51-59. doi: 10.1332/174426410X482999.

24. Drummond MF, Jefferson TO. Guidelines for authors and peer reviewers 
medRxiv preprint doi: https://doi.org/10.1101/2020.12.14.20248198; this version posted December 16, 2020. The copyright holder for this preprint (which was not certified by peer review) is the author/funder, who has granted medRxiv a license to display the preprint in

perpetuity.
It is made available under a CC-BY 4.0 International license .

of economic submissions to the BMJ. The BMJ Economic Evaluation Working Party. BMJ. 1996 Aug 3;313(7052):275-83.

25. Husereau D, Drummond M, Petrou S, Carswell C, Moher D, Greenberg D, et al. Consolidated Health Economic Evaluation Reporting Standards (CHEERS) statement. Eur. J. Health Econ. 2013 Jun;14(3):367-72. 